\title{
A quantitative genetic analysis of reproductive allocation in the cotton stainer bug Dysdercus fasciatus
}

\author{
F. K. KASULE \\ Department of Zoology, University of Dar es Salaam, P.O. Box 35064, Dar es Salaam, Tanzania
}

\begin{abstract}
Observations were made of genetic variability of reproductive allocation in a population of the cotton stainer bug Dysdercus fasciatus. In addition, genetic correlations between reproductive allocation and maternal size and between performances of reproductive allocation in two moisture environments were investigated. Groups of siblings were grown in either a low or a high moisture environment. Heritability estimates were approximately 1.0 in the low environment and 0.7 in the high environment. There was a tight and positive genetic association between reproductive allocation and maternal size in both environments. Some 50 per cent of the phenotypic variance in reproductive allocation across environments was due to genotype-by-environment interactions. The correlation between performances in low and high environments was less than unity, and environmental sensitivity and mean performance were negatively associated. These results indicate that the population sampled would respond to directional selection, with mean peformance and phenotypic plasticity of reproductive allocation moving in opposite directions.
\end{abstract}

Keywords: Dysdercus fasciatus, genetic variability, reproductive allocation.

\section{Introduction}

Studies of reproductive allocation (defined as the ratio of clutch weight to total maternal weight) have increased over the past two decades. Williams (1966) suggested that the ratio of clutch size to maternal size could be used as an index of reproductive effort. Since that time, important advances have been established; for instance, that the ratio of clutch to maternal size and other similar measures are potentially misleading when used as indices of reproductive effort (Hirshfield \& Tinkle, 1975; Tinkle \& Hadley, 1975; Vitt \& Congdon, 1978; Hart \& Begon, 1982; Thompson, 1982; de Souza Santos \& Begon, 1987). Other research has emphasized that egg production sometimes involves risks over and above the simple diversion of resources. During periods of egg production, the size of the gonads increases by as much as 50 per cent in fishes (Gerking, 1959) and lizards (Tinkle, 1969) and 35 per cent in salamanders (Tiley, 1968). Reproducing individuals may, then, be more vulnerable to predation or less efficient at food capture because of the increased weight and bulk of their reproductive organs (e.g. Vitt \& Congdon, 1978; Bauwens \& Theon, 1981; Vitt, 1981, Magnusson et al., 1985; Shine,1980, 1988).

These and many other studies attempt to correlate phenotypic characteristics surrounding reproductive allocation with probable selective agents (e.g. amount of reproductive allocation with foraging or predator evasion tactics). Shine (1988, p.17) conjectured that the reproductive allocation '... favored by natural selection may depend on the degree to which the gravid female will be physically burdened by the clutch.' However, there are no studies to demonstrate that the allocation of maternal reproductive effort in species studied thus far has a genetic basis. For any adaptation to evolve by natural selection there must be heritable variation for the character in question. Therefore, a first step in understanding how a particular adaptation will evolve under changing environmental conditions is to establish the levels of additive genetic variation for the characters involved.

As a part of an investigation into genetic variation and fitness (Kasule, 1991), observations were made of adult size and clutch size in the cotton stainer bug Dys- 
dercus fasciatus Signoret. The data gathered also allowed for the examination of reproductive allocation in this species. The objectives of the present study were threefold: (1) to determine the amount of reproductive allocation in two moisture environments, (2) to provide an estimate of genetic variation for reproductive allocation in the two environments, and (3) to investigate if reproductive allocation is genetically associated with maternal size in $D$. fasciatus. Genetic correlation between characters may explain the maintenance of additive genetic variance in populations (Lande, 1982; Rose, 1982; Charlesworth, 1984).

\section{Materials and methods}

\section{Experimental design}

The $D$. fasciatus used here were second-generation progeny of parents collected in the field, and were the same as those used in a previous study (Kasule, 1991). The experiment used a mating design in which two unrelated virgin females (dams) were mated to one male (sire) to generate both full-sib and half-sib families (Robertson, 1959; Falconer, 1981), and involved the growth of groups of sibling larvae in either a stressful or a benign moisture environment (henceforth, low and high environments, respectively). This procedure allowed genetic variance of reproductive allocation in response to environment to be evaluated. Moisture was used as an environmental variable in this experiment because it seemed that it may be an important factor affecting life-history components, and ultimately fitness in Dysdercus species. Dysdercus species are seed predators of Malvales (Pearson, 1958). Both larvae and adults feed by injecting saliva into the seed and sucking the partially-digested soup. Very dry conditions in the field have been associated with migration of Dysdercus species from areas where seeds were still plentiful (Whitfield, 1933, Pearson, 1958). The detailed rearing methodology and materials are given in Kasule (1991).

To investigate reproductive allocation (RA), daughters of each male were weighed individually to $0.1 \mathrm{mg}$ within $24 \mathrm{~h}$ of adult emergence to obtain their weights at adult eclosion (daughters had a mean eggto-adult developmental period of about 34 days in the low environment and 32 days in the high environment). Each daughter was then confined with a male in a cage containing kapok (Ceiba petandra L.) seeds, and returned to the environment in which she had grown to lay eggs (6-9 days after adult emergence). The wet weight of eggs laid in the first clutch by each of these females was scored and maternal weight (MW) was approximated as

$\mathrm{MW}=$ weight at adult eclosion

+ weight of eggs in first clutch.

Reproductive allocation was calculated as

$\mathrm{RA}=$ Clutch weight $/ \mathrm{MW}$

or its logarithmic transformation

$\log \mathrm{RA}=\log$ clutch weight $-\log \mathrm{MW}$.

In all, 26 sires were successfully mated to 52 dams. The resulting families yielded 312 test daughters, i.e. six per full-sib family, in each environment.

\section{Statistical analysis}

Reproductive allocation was examined using a nested model II analysis of variance (covariance) (Sokal \& Rohlf, 1981) to determine the components of variance (covariance) for comparisons between sires, within sires between dams, and within families (Robertson, 1959; Falconer, 1981). A balanced dataset was used in the analyses (see Kasule, 1991). The assumptions underlying the analysis of variance (ANOVA) include homoscedasticity of variances and normally distributed residual variation (Sokal \& Rohlf, 1981). Data were transformed to $\log _{10}$ to guard against violation of these assumptions (Sokal \& Rohlf, 1981).

The genetic model for the variance (covariance) of character $Y$, assuming no epistasis (Falconer, 1981) is:

$V_{\mathrm{Y}}=V_{\mathrm{P}}=V_{\mathrm{A}}+V_{\mathrm{D}}+V_{\mathrm{C}}+V_{\mathrm{E}}$

where $V_{\mathrm{P}}=$ phenotypic variance, $V_{\mathrm{A}}=$ additive genetic variance, $V_{\mathrm{D}}=$ dominance genetic variance, $V_{\mathrm{C}}=$ common environmental (maternal-effects) variance and $V_{\mathrm{E}}=$ residual environmental variance.

The intraclass coefficient of sires for the present design provides the best unbiased estimate of additive genetic variance or covariance $\left(C O V_{\mathrm{A}}\right)$. The proportion due to $V_{\mathrm{A}}\left(C O V_{\mathrm{A}}\right)$ was calculated as four times the variance (covariance) due to sires $\left(V_{s}\right)$ divided by the total phenotypic variance (covariance):

$V_{\mathrm{A}}=4 V_{\mathrm{s}} / V_{\mathrm{P}}$

so that $V_{\mathrm{A}}$ is the narrow-sense heritability $\left(h^{2}\right)$.

Estimates of heritabilities from small samples, such as the one studied here, offer, at best, only a qualitative picture. Approximate standard errors (Falconer, 1981) were attached to the heritability estimates to enable the reader to judge how much reliance to place on the results.

The intraclass coefficient of dams includes variances (covariances) due to additive gene effects, dominance, 
and maternal effects. Therefore, the difference between the sire and dam components gives an estimate of the non-additive genetic plus maternal-effects component of variance $\left(V_{\mathrm{NA}+\mathrm{M}}\right)$ or covariance $\left(C O V_{\mathrm{NA}+\mathrm{M}}\right)$ :

$$
V_{\mathrm{NA}+\mathrm{M}}=4\left(V_{\mathrm{d}}-V_{\mathrm{s}}\right) / V_{\mathrm{P}}
$$

where $V_{\mathrm{d}}$ is the variance (covariance) due to dams.

The residual environmental component of variance (covariance) was calculated as

$V_{\mathrm{E}}=\left[V_{\mathrm{r}}-\left(3 V_{\mathrm{d}}-V_{\mathrm{s}}\right)\right] / V_{\mathrm{P}}$

where $V_{\mathrm{r}}$ is the variance (covariance) attributable to progenies.

Some variance estimates were negative, probably due to the small sample used; thus the results presented in this paper must be regarded with caution. Variance components with negative estimated values are reported as zero.

Regression $\left(b_{(\mathrm{xy})}\right)$ and correlation $\left(r_{(\mathrm{xy})}\right)$ coefficients for phenotypic, additive genetic, non-additive genetic plus maternal-effects, and residual environmental effects were calculated from equations of the following forms:

$b_{(\mathrm{xy})}=\operatorname{CO} V_{(\mathrm{xy})} / V_{(\mathrm{x})}$

and

$r_{(x y)}=\operatorname{COV} V_{(\mathrm{xy})} / \sqrt{\left(V_{(\mathbf{x})} X V_{(\mathrm{y})}\right.}$

where $C O V_{(\mathrm{xy})}$ is the appropriate covariance component of RA with $\mathrm{MW}$ and $V_{(\mathrm{x})}$ and $V_{(\mathrm{y})}$ are the appropriate variance components of $\mathrm{MW}$ and $\mathrm{RA}$, respectively. Correlations are interpretable for effects which had non-zero causal variance components for both characters.

Many life-history characters are correlated with body size (Peters, 1983) and an allometric equation of the form $L=a W^{b}$

or its logarithmic transformation

$\log L=b \log W+\log a$,

where $L$ is the life-history character and $W$ is the body weight, is commonly used to describe such a relationship. Thus, with logarithmically transformed data each of the above regressions gives an estimate of $b$. Standard errors were calculated for the phenotypic regression as per Sokal \& Rohlf (1981); those of the other regressions have not been formulated and are, therefore, not given. Phenotypic correlations are reported with 95 per cent confidence limits estimated by the $z$-transformation (Sokal \& Rohlf, 1981).
Standard errors for the other correlations were calculated as suggested by Falconer (1981).

Genotype $\times$ environment interactions $(g \times e$ interactions) in a partially hierarchical two-way ANOVA, and genetic correlations between the same character across environments (below), were calculated as measurements of genetic variance of a character in response to environment. A significant $g \times e$ interaction signifies that genotypes are expressed differently in the two environments.

Falconer $(1952,1990)$ considers a character measured in two different environments in a genetic context as two different characters which are genetically correlated. Via (1984) gives several methods of calculating genetic correlations across environments, including the use of family means. This procedure estimates the broad-sense genetic correlation (including covariances between non-additive effects) but the estimate is deflated by the presence of the withinfamily (error) variance component in the denominator and may be inflated by the presence of an effect of the common family environment in the numerator. Nonetheless, because estimated variances of the family mean correlation tend to be smaller than those of the variance component correlation, the use of the family mean correlation should be a more powerful statistical test of whether the genetic covariance is significantly greater than zero. In the absence of effects of the common family environment, as the family size increases, the family mean correlation approaches the true genetic correlation (Via, 1984). To apply Falconer's (1952) idea, full-sib family means of reproductive allocation and maternal size were calculated in low and high environments, and were used to determine the covariance of performance in the two environments $\left(C O V_{\mathrm{HL}}\right)$. In addition, values were determined for the variance in the low environment $\left(V_{\mathrm{L}}\right)$, the variance in the high environment $\left(V_{\mathrm{H}}\right)$, the variance of means $\left(V_{M}\right)$, and the covariance of means and sensitivities $\left(C O V_{M S}\right)$ (Falconer, 1990). Sensitivity refers to the difference in mean expression of a character in two environments, and is equivalent to the reaction norm (Falconer, 1990) of Schmalhaussen (1949).

A value of $r_{\mathrm{HL}}$ approaching 1 means that the character is influenced by nearly the same genes in the two environments (there is no variation among families in sensitivity). A value of $r_{\mathrm{HL}}$ around zero means that phenotypes in each environment are influenced either by different alleles or differently by the same alleles (there is variation among families in sensitivity), and therefore could have independent evolutionary trajectories. A low value of $r_{\mathrm{HL}}$ translates into significant $g \times e$ interaction (Falconer, 1990). 


\section{Results}

\section{Reproductive allocation}

Mean values of reproductive allocation and maternal size measured on siblings in low and high environments are shown in Table 1 . Analysis of variance revealed significant heterogeneity between the corresponding pairs of values in low and high environments.

\section{Variance components}

Reproductive allocation. The results of analysis of variance are given in Table 2 . The estimates of significant variation between sires in low $(P<0.025)$ and high $(P<0.05)$ environments indicate the presence of overall additive genetic variance for this character.
There is also a significant effect of dams in both environments (Table 2).

Variance components appear in Table 2. The between-sire and between-dam observational variance components are similar, which suggests that nonadditive genetic and/or maternal effects are unimportant in RA variability in this sample of $D$. fasciatus. Hence, heritability estimates, based on sires, dams and their combination, could yield similar values. The heritability of reproductive allocation is estimated from the sires component as $0.96 \pm 0.34$ in the low environment and $0.68 \pm 0.264$ in the high environment. There is, however, a large residual component in the high environment, which suggests that some of the variation in reproductive allocation in this environment is due to effects unique to individual females.

Table 1 Means ( 95 per cent confidence limits) and ANOVA of reproductive allocation $(\dot{\mathrm{R}} \mathrm{A})$ and maternal size $(\mathrm{MW})(\mathrm{mg})$ for siblings grown in low and high moisture environments

\begin{tabular}{llllll}
\hline Moisture & & \multicolumn{2}{c}{ ANOVA } & & \\
\cline { 1 - 1 } \cline { 5 - 6 } Low & High & & d.f. & $F$ & $P$ \\
\hline RA & & & & \\
$\quad 0.352$ & 0.386 & 1,416 & 290.46 & $\ll 0.001$ \\
$\quad(0.3475,0.3573)$ & $(0.3837,0.389)$ & & & \\
MW & & & & \\
$\quad 165.5$ & 215.5 & 1,416 & 1192.84 & $\ll 0.001$ \\
$(162.93,168.27)$ & $(213.3,217.77)$ & & & \\
\hline
\end{tabular}

Table 2 Analysis of variance and variance components for log reproductive allocation in Dysdercus fasciatus raised in low and high moisture environments. $V_{\mathrm{A}}$ is the narrow-sense heritability

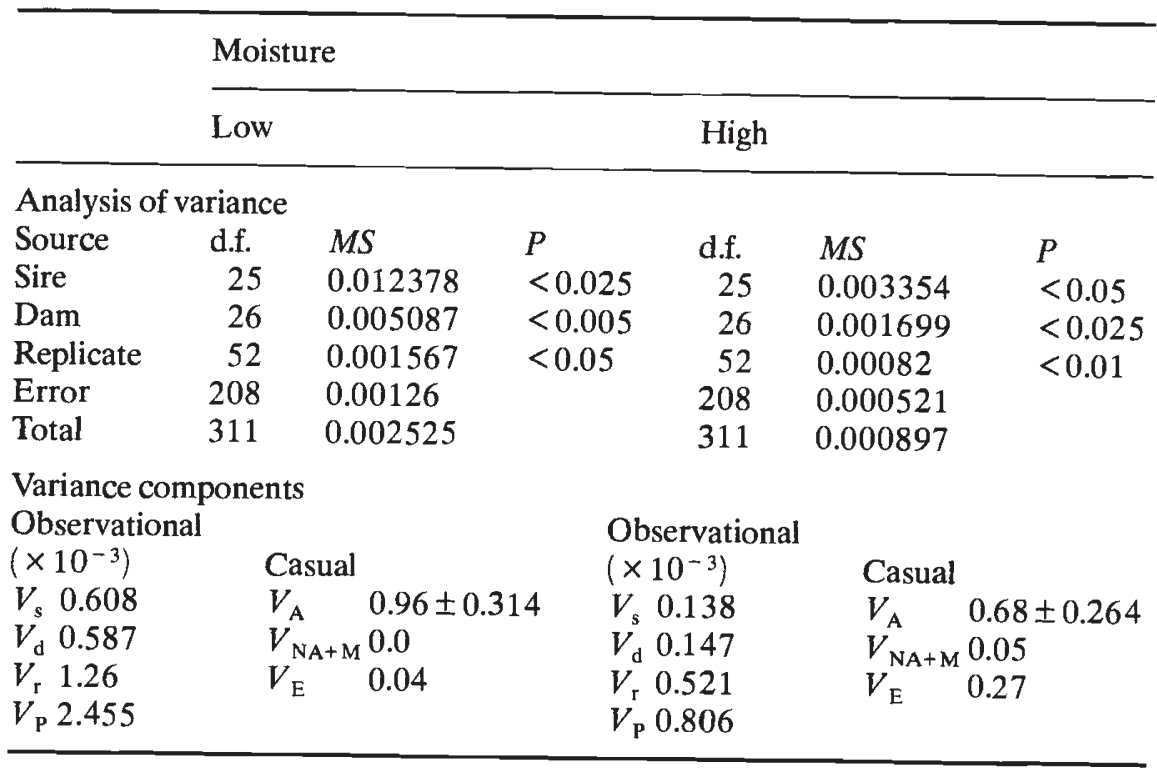


Maternal size. In contrast, for maternal size, analysis of variance indicates significant effects of both sires and dams only in the high environment; in the low environment the sire term is not significant (Table 3 ).

Observational components of variance (Table 3) show that there is a substantial dam component both in the low and high environments. This indicates that a portion of the variation in the size of daughters is due to maternal effects, which confounds dominance with the common environmental effects experienced by full sibs. This is especially true in the low environment where there is virtually no additive genetic component to phenotypic variability in $\log$ maternal size. The between-sires component provides, therefore, the better unbiased estimate of additive genetic variability in maternal size. The heritability of this character in the high environment is estimated as $0.58 \pm 0.243$. Assuming dominance to be small, the effects of a shared larval environment are estimated to explain 0.877 and 0.151 of the phenotypic variance in maternal size in low and high environments, respectively. Residual environmental effects contribute 0 and 27 per cent to the phenotypic variance in maternal size in low and high environments, respectively.

\section{Covariance components}

Reproductive allocation and maternal size should be positively associated to some degree due to part-whole correlation (Sokal \& Rohlf, 1981), because maternal size was scored as eclosion weight plus clutch weight. A summary of the results is given in Table 4. As expected,

Table 3 Analysis of variance and variance components for log maternal size in Dysdercus fasciatus siblings raised in low and high moisture environments. $V_{\mathrm{A}}$ is the narrow-sense heritability

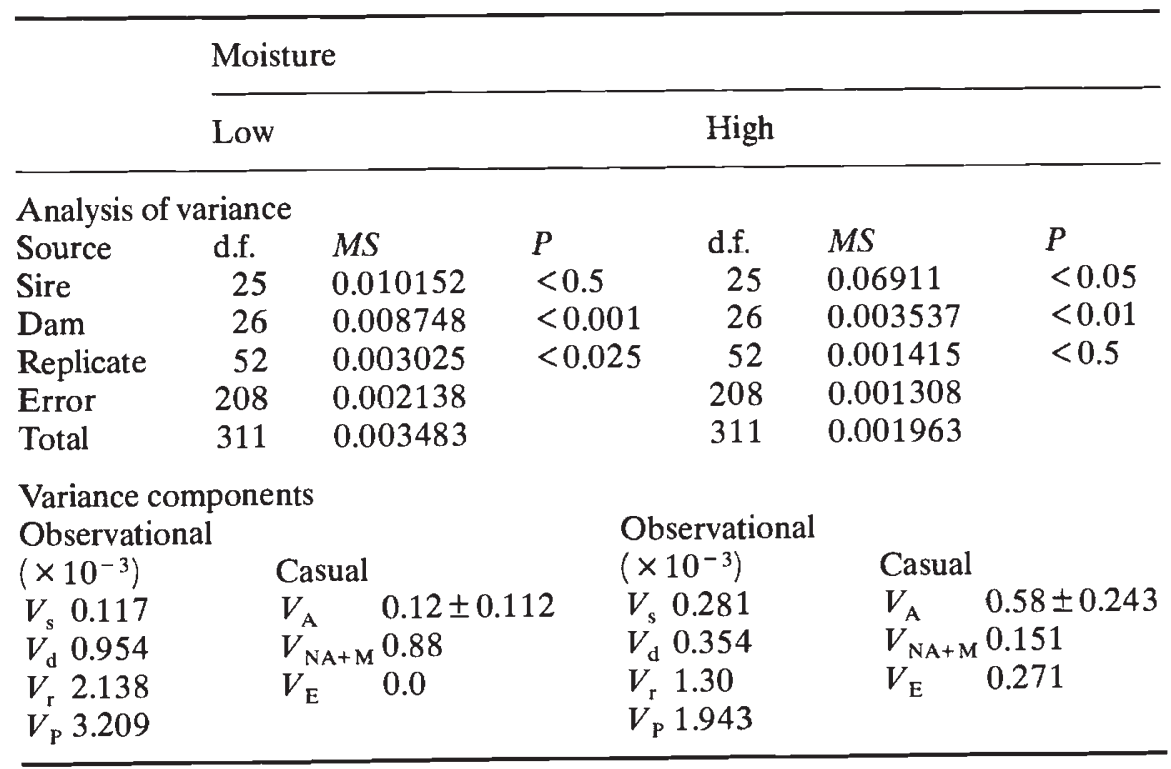

Table 4 Partition of the phenotypic covariance for reproductive allocation with maternal size in Dysdercus fasciatus siblings raised in low and high moisture environments. The additive genetic component $(A)$ is the co-heritability of the two traits. Numbers in parentheses are the 95 per cent confidence intervals estimated by the $z$-transformation

\begin{tabular}{|c|c|c|c|c|c|c|}
\hline & \multicolumn{3}{|c|}{ Low moisture } & \multicolumn{3}{|c|}{ High moisture } \\
\hline & Covariance & Allometry & Correlation & Covariance & Allometry & Correlation \\
\hline $\mathbf{P}$ & & 0.33 & $\begin{array}{l}0.328 \\
(0.28,0.473)\end{array}$ & & 0.24 & $\begin{array}{l}0.356 \\
(0.254,0.361)\end{array}$ \\
\hline A & 0.59 & 1.69 & $0.74 \pm 0.17$ & 0.90 & 0.64 & $0.99 \pm 0.05$ \\
\hline $\mathrm{NA}+\mathrm{M}$ & 0.41 & 0.35 & - & 0.10 & 0.56 & 0.87 \\
\hline $\mathbf{E}$ & 0.0 & & & 0.0 & & \\
\hline
\end{tabular}


phenotypic association between allocation and maternal size are positive and significant in both low and high environments. The allometric coefficients (Table 4) are significantly different from zero (low: $t=7.569$, d.f. $=310, \quad P<0.001$, high: $t=5.247, \quad$ d.f. $=310$, $P<0.001)$. The allometric relationships for reproductive allocation in siblings raised in low versus high environments are not significantly different $(F=1.87$, d.f. $=1 / 620, P \simeq 0.17$ ).

There is a significant and positive genetic association between reproductive allocation and maternal size in both environments. An estimate of covariance components (Table 4) indicates that roughly 60 and 90 per cent of the phenotypic association of reproductive allocation with maternal size in low and high environments, respectively, is of an additive genetic nature. In the low environment, the heritability of maternal size is 1.07 times its standard error (Table 3). Given the nonsignificant heritable variation in maternal size, the genetic correlation in the low environment (Table 4) is of little significance; for instance, it would not be expected to produce a constraint on selection or indirect response. Non-additive genetic or maternal effects explain some 40 and 10 per cent of the total phenotypic covariance of reproductive allocation with maternal size in the low and high environments, respectively. There is no residual environmental component to reproductive allocation-maternal size phenotypic covariability in the population sampled.

\section{Genetic variance in response to environment}

$g \times e$ interactions. Table 5 shows the results of a twoway ANOVA of reproductive allocation and maternal size. The sire-moisture interaction is not significant but the dam-moisture interaction is, which indicates $g \times e$ interaction for both characters. The importance of the $g \times e$ interaction is readily seen in Table 6 which shows that additive and non-additive interactions together comprise some 50 per cent of the overall genetic variance in reproductive allocation and maternal size. The non-additive component is the larger of the two components of $g \times e$ interaction variance in both characters consistent with the significant interaction between full-sib families and moisture (Table 5).

The heritabilities (as $V_{\mathrm{A}}$ ) of reproductive allocation and maternal size are also shown in Table 6, estimated from the combined two-way ANOVA. They are generally lower than those given earlier (Tables 2 and 3 ) for these characters due to genetic variation taken up by $g \times e$ interaction, but estimate what would occur in a population in a heterogeneous environment. These findings indicate that high heritabilities measured in the laboratory under one set of environmental conditions may
Table 5 Two-way ANOVA of log reproductive allocation (RA) and log maternal size (MW) in Dysdercus fasciatus siblings raised in two moisture environments

\begin{tabular}{lrlll}
\hline Source & d.f. & $M S$ & Error term & $P$ \\
\hline RA & & & & \\
Moisture & 1 & 0.258803 & Residual & $<0.001$ \\
Sire & 25 & 0.011168 & Dam & $<0.005$ \\
Dam & 26 & 0.003293 & Dam $\times$ moisture & $>0.05$ \\
Sire $\times$ moisture & 25 & 0.004564 & Dam $\times$ moisture & $>0.05$ \\
Dam $\times$ moisture & 26 & 0.003493 & Replicate & $<0.001$ \\
Replicate & 104 & 0.001194 & Residual & $<0.01$ \\
Residual & 416 & 0.000891 & & \\
Total & 623 & 0.002124 & & \\
MW & & & & $<0.001$ \\
Moisture & 1 & 2.055289 & Residual & $>0.05$ \\
Sire & 25 & 0.010804 & Dam & $>0.05$ \\
Dam & 26 & 0.007782 & Dam $\times$ moisture & $>0.05$ \\
Sire $\times$ moisture & 25 & 0.006258 & Dam $\times$ moisture & $>0.005$ \\
Dam $\times$ moisture & 26 & 0.004503 & Replicate & $<0.0025$ \\
Replicate & 104 & 0.00222 & Residual & $<0.025$ \\
Residual & 416 & 0.001723 & & \\
Total & 623 & 0.006018 & & \\
\hline & & & & \\
\hline
\end{tabular}

Table 6 Causal variance components for reproductive allocation (RA) and maternal size (MW) in Dysdercus fasciatus siblings raised in two moisture environments. $V_{\mathrm{I}(\mathrm{A})}=$ additive genetic interaction, $V_{\mathrm{I}(\mathrm{NA}+\mathrm{M})}=$ non-additive genetic plus maternal-effects interaction

\begin{tabular}{lll}
\hline Source & RA & MW \\
\hline$V_{\mathrm{A}}$ & $0.43 \pm 0.148$ & $0.19 \pm 0.099$ \\
$V_{\mathrm{NA}+\mathrm{M}}$ & 0.0 & 0.22 \\
$V_{\mathrm{I}(\mathrm{A})}$ & 0.12 & 0.22 \\
$V_{\mathrm{I}(\mathrm{NA}+\mathrm{M})}$ & 0.38 & 0.36 \\
$V_{\mathrm{E}}$ & 0.07 & 0.01 \\
\hline
\end{tabular}

not necessarily imply that high levels of genetic variation are expressed in the field where environmental conditions are heterogeneous.

Genetic correlations between the same character across environments. A summary of the results is given in Table 7 which shows variances for reproductive allocation and maternal size in low and high environments, the variance of means and correlations between performances in the two environments and between mean and sensitivity. The correlation coefficient for family means in the two environments $\left(r_{\mathrm{HL}}\right)$ was significantly less than unity for reproductive allocation $(t=-24.16$, $P \ll 0.001)$ and maternal size $(t=-24.61, P \ll 0.001)$. Hence the significant interaction between full-sib 
families and moisture (Table 5) is due to variation among the families in environmental sensitivity.

The correlation between sensitivity and mean performance is negative because the variance is greater in the low than in the high environment (Table 7). The association between sensitivity and mean performance may be due to a scale effect, however, even if data are transformed to a scale that equalizes the variances in the different environments (Falconer, 1990). As a measure of the amount of genotypic variation ascribable to real sensitivity, $\left(1-r_{\mathrm{MS}}^{2}\right)$ was calculated for each character: the values were 0.67 and 0.89 for reproductive allocation and maternal size, respectively.

\section{Discussion}

\section{Reproductive allocation in Dysdercus fasciatus}

A reproducing $D$. fasciatus female had, on average, 0.37 times the mass of her body in resources to allocate to a clutch (Table 1). Moisture had a profound effect on reproductive allocation in these bugs, probably via its effects on the efficiency of converting assimilated material into biomass (Martin \& van't Hoff, 1988). Individuals grown in the low environment were 23 per cent lighter than their siblings grown in the high environment, and large females had a greater quantity of resources to allocate, irrespective of the environment (Table 4).

The proportionality constant describing the relationship between maternal size and reproductive allocation was (albeit not significantly) greater for siblings raised in the low rather than in the high environment (Table 4). As siblings in the low environment were lighter than those in the high environment (Table 1), this finding supports the hypothesis that smaller females have a relatively large proportion of resources available for reproduction (Reiss, 1985). A similar pattern of allocation is known from other insects (e.g. Llewellyn \& Brown, 1985; de Souza Santos \& Begon, 1987).

There are no comparable published data on reproductive allocation in insects. However, studies comparable to this one exist on other taxa. Vitt \& Congdon (1978) reported average values of reproductive allocation, calculated from both mass and energy data for 22 lizard species. They found that values from the mass data were in the range of $0.131-0.406$ $(\bar{x} \pm$ s.d. $=0.245 \pm 0.081)$; those from energy data, in the 0.268-0.568 range ( $\bar{x} \pm$ s.d. $=0.387 \pm 0.091)$. Seigel \& Fitch (1984) found that average values of reproductive allocation were in the 0.11-0.29 range $(\bar{x} \pm$ s.d. $=0.23 \pm 0.05)$ for 16 species of aquatic snakes, and in the $0.11-0.55$ range $(\bar{x} \pm$ s.d. $=0.35 \pm 0.08)$ for
Table 7 Variances in low $\left(V_{\mathrm{L}}\right)$ and high $\left(V_{\mathrm{H}}\right)$ moisture environments, the variance of means $\left(V_{\mathrm{M}}\right)$, and the correlation coefficients between performances in the two environments $\left(r_{\mathrm{HL}}\right)$ and between mean and sensitivity $\left(r_{\mathrm{MS}}\right)$ for reproductive allocation (RA) and maternal size $(\mathrm{MW})$ in Dysdercus fasciatus siblings. The variances $\left(\times 10^{-3}\right)$ are genotypic

\begin{tabular}{llllll}
\hline Source & $V_{\mathrm{L}}$ & $V_{\mathrm{H}}$ & $V_{\mathrm{M}}$ & $r_{\mathrm{HL}}$ & $r_{\mathrm{MS}}$ \\
\hline RA & 1.438 & 0.42 & 0.595 & 0.335 & -0.571 \\
MW & 1.662 & 0.852 & 0.794 & 0.277 & -0.334 \\
\hline
\end{tabular}

77 terrestrial species. Willows (1987) examined reproductive allocation in energetic terms for two populations of Ligia oceanica (woodlouse), at two different sites. He found a value of 0.337 for one population and 0.328 for the other.

Phylogenetic constraints may render comparisons across phylogenetic lines invalid. Nonetheless, these examples indicate that the mean values of reproductive allocation measured on $D$. fasciatus (Table 1) appear to be of the same order of magnitude as those observed on other animals.

\section{Genetics of reproductive allocation}

Despite sample size problems this study has demonstrated significant genetic variation for reproductive allocation in the population sampled. The genetic architecture of reproductive allocation varied between environments. Both additive genetic and residual environment effects were important in the phenotypic expression of reproductive allocation in the high environment. However, for siblings grown in the low environment additive genetic variance opened up so that the genetic architecture became almost entirely additive genetic (Table 2).

There was a virtual absence of a non-additive genetic or maternal-effects contribution to the phenotypic variance of reproductive allocation (Table 2). One interpretation of this result is that variation in reproductive output per unit of body mass among daughters is likely to be more dependent upon the way resources are allocated between survival and reproduction than upon variation in the effects of a shared larval environment. Hence, maternal effects via, for instance, egg quality are not likely to affect reproductive allocation.

The relative magnitudes of the components of phenotypic variance in log maternal size also differed between environments but maternal size appeared to follow a different pattern with respect to the degree of genetic influence. Substantial additive genetic variance 
remained segregating for maternal size only in the high environment; in a low environment, maternal size was a character for which the genetic architecture become almost entirely non-additive genetic or conditioned almost entirely by maternal effects (Table 3 ). Substantial non-additive genetic and/or maternal effects and low heritabilities were also reported in this population for adult size and fecundity scored in the low environment (Kasule, 1991).

Two features of these results make them of particular interest. First, the heritable components of reproductive allocation and maternal size are strongly modified by the rearing environment. Because selection can be effective only in proportion to the amount of genetic variation present (Fisher, 1930), this finding may explain the maintenance of genetic variance for populations in heterogeneous environments. The maintenance of genetic variation in quantitative characters, especially those associated with fitness, is a central issue of evolutionary biology (e.g. Lande, 1975; Rose, 1982; Charlesworth, 1984, 1987, Turelli, 1984; Keightley \& Hill, 1988). The data in Tables 2 and 3 imply that the population sampled has the potential for condition-dependent evolution, with the response to selection being a function of the conditions of the environment. This suggestion is very strongly upheld by the $g \times e$ interactions data (Table 6) and genetic correlation between the same character in different environments (Table 7). Both measures indicate that mutations are expressed differently in various environments. If genotypic expression is environmentdependent, then different genotypes will be selected under different conditions in a heterogeneous environment, resulting in balanced polymorphism, even if selection is directional. Giesel et al. (1982) and Murphy et al. (1983) have discussed how this sort of balancing selection may operate.

$g \times e$ interactions and genetic correlations between the same character across environments also have bearing on the general phenomenon of phenotypic plasticity (Scheiner \& Goodnight, 1984; Via \& Lande, 1985, 1987; Schlichting, 1986). Phenotypic plasticity has been widely implicated as an important element in the catenary process of adaptation to environmental instabilities (Wright, 1931; Schmalhausen, 1949; Bradshaw, 1965; Capinera, 1979; Crump, 1981; Kaplan \& Cooper, 1984; Schlichting, 1986). The substantial $g \times e$ interaction variance that remains (Table 6) and the genetic correlations between the same character across environments, which are significantly less than one (Table 7), demonstrated that there is high plasticity for reproductive allocation and maternal size, and genotypic difference in phenetic responses of these characters in the population studied.
Bradshaw (1965) suggested that evolution could lead to either a greater or less amount of plasticity. This study indicates that the population sampled could respond to directional selection with mean performance and plasticity (sensitivity) moving in opposite directions (Table 7).

The second interesting feature of the results is that there is abundant genetic variability for reproductive allocation, variation that could respond to selection (Table 2). What maintains this variance? The data presented in Table 4 suggest that the quantity of resources that a female allocates to reproduction evolved in close relation to the size of her body. If genotypic expression of maternal size is environment-dependent in the way this study has shown it to be, genetic variation would be expected in reproductive allocation as a result of a correlated response to variable selection pressures on maternal size.

\section{Acknowledgements}

I would like to thank J. Goha for technical assistance and referees for constructive comments on the manuscript.

\section{References}

BAUWENS, D. AND THEON, C. 1981. Escape tactics and vulnerability to predation associated with reproduction in the lizard Lacerta vivipara. J. Anim. Ecol., 50, 733-743.

BRADSHAW, A. D. 1965 . Evolutionary significance of phenotypic plasticity in plants. Adv. Genet., 13, 115-153.

CAPINERA, J. L. 1979. Qualitative variation in plants and insects: Effect of propagule size on ecological plasticity. Am. Nat., 114, 350-361.

CHARLESWORTH, B. 1984. The evolutionary genetics of life histories. In: Shorrocks, B. (ed.), Evolutionary Ecology, Blackwell Scientific Publications, Oxford, pp. 117-137.

CHARLESWORTH, B. 1987. The heritability of fitness. In: Bradburry, J. W. and Anderson, M. B. (eds), Sexual Selection: Testing the Alternatives, John Wiley \& Sons Ltd, Chichester, pp. 21-40.

CRUMP, M. L. 1981. Variation in propagule size as a function of environmental uncertainty for tree frogs. Am. Nat., 117, 724-737.

FALCONER, D. S. 1952. The problem of environment and selection. Am. Nat., 86, 293-298.

FALCONER, D. S. 1981. Introduction to Quantitative Genetics, 2nd edn, Longman, London.

FALCONER, D. S. 1990. Selection in different environments: effects on environmental sensitivity (reaction norm) and on mean performance. Genet. Res., 56, 57-70.

FISHER, R. A. 1930. The Genetical Theory of Natural Selection, Cambridge University Press, London.

GERKING, S. D. 1959. Physiological changes accompanying aging in fishes. In: Wolsteinholme, E. and O'Connor, M. (eds), Ciba Foundation Coloquia on Aging, I, Churchill 
Livingstone, London, pp. 181-211.

GIESAL, J. T., MURPHY, P. A. AND MANLOVE, M. N. 1982. The influence of temperature on genetic interrelationships of life history traits in a population of Drosophila melanogaster, Am. Nat., 119, 464-479.

HART, A. AND BEGON, M. 1982. The status of general reproductive-strategy theories, illustrated in winkles. Oecologia, 52 , 37-42.

HIRSHFIELD, M. F. AND TINKLE, D. W. 1975. Natural selection and the evolution of reproductive effort. Proc. Natl. Acad. Sci., U.S.A., 72, 2227-2231.

KAPLAN, R. H. AND COOPER, W. S. 1984. The evolution of developmental plasticity in reproductive characteristics: An application of the 'adaptive coin-flipping' principle. Am. Nat., 123, 393-410.

KASULE, F. K. 1991. Quantitative variation in adult size and fecundity of the cotton stainer bug Dysdercus fasciatus. Heredity, 66, 273-279.

KEIGHTLEY, P. D. AND HILL, W. G. 1988. Quantitative genetic variability by mutation-stabilizing selection in finite populations. Genet. Res., 52, 33-43.

LANDE, R. 1975. The maintenance of genetic variability by mutation in a polygenic character with linked loci. Genet. Res., 26, 221-235.

LANDE, R. 1982. A quantitative genetic theory of life history evolution. Ecology, 63, 607-615.

LLEWELLYN, M. \& BROWN, U. K. 1985. A general relationship between adult weight and the reproductive potential of aphids. J. Anim. Ecol., 54, 663-673.

MAGNUSSON, W. E., De PAIVA, L. J., Da ROCHA, R. M., FRANKE, G. R. KASPER, L. A. AND LIMA, A. P. 1985. The correlates of foraging mode in a community of Brazilian lizards. Herpertologia, 41, 324-332.

MARTIN, M. M. AND VAN'T HOFF, H. M. 1988. The cause of reduced growth of Manduca sexta larvae on low-water diet: increased metabolic processing costs or nutrient limitation? J. Insect. Physiol., 34, 515-525.

MURPHY, P. A. GIESEL, J. T. AND MANLOVE, N. N. 1983. Temperature effects on life history variation in Drosophila simulans. Evolution, 42, 774-783.

PEARSON, E. O. 1958. The Insects Pest of Cotton in Tropical Africa, Commonwealth Institute of Entomology, London.

PETERS, R. H. 1983. The Ecological Implications of Body Size. Cambridge University Press, Cambridge.

REISS, M. J. 1985. The allometry of reproduction: why larger species invest relatively less in their offspring. J. Theor. Biol. 113, 529-544.

ROBERTSON, A. 1959. Experimental design in the evaluation of genetic parameters. Biometrics, 15, 219-226.

ROSE, R. M. 1982. Antagonistic pleiotrophy, dominance and genetic variation. Heredity, 48, 63-78.

SCHEINER, S. M. AND GOODNIGHT, C. J. 1984. The comparison of phenotypic plasticity and genetic variation in populations of the grass Danthonia spicata. Evolution, 38, 845-855.

SCLICHTING, C. D. 1986. The evolution of phenotypic plasticity in plants. Ann. Rev. Ecol. Syst., 17, 667-693.

SChmalhausen, I. T. 1949. Factors of Evolution, Blackston, Philadelphia.

SEIGEL, R. A. AND FITCH, H. S. 1984. Ecological patterns of relative clutch mass in snakes. Oecologia, 61, 293-301.

SHINE, R. 1980. Costs of reproduction in reptiles. Oecologia, 46, 92-100.

SHINE, R. 1988. Constraints on reproductive investment: a comparison between aquatic and terrestrial snakes. Evolution, 42, 17-27.

SOKAL, R. R. AND ROHLF, F. J. 1981. Biometry, 2nd edn, W. H. Freeman, San Francisco.

De SOUZA SANTOS, P., JR AND BEGON, M. 1987. Survival costs of reproduction in grasshoppers. Funct. Ecol., 1, 215-221.

THOMPSON, R. J. 1982. The relationship between food ratio and reproductive effort in the green sea urchin. Oecologia, 56, 50-57.

TILLEY, S. G. 1968. Size-fecundity relationships in five desmograthine salamanders. Evolution, 22, 806-816.

TINKLE, D. W. 1969. The concept of reproductive effort and its relation to the evolution of life histories in lizards. Am. Nat., 103, 501-516.

TINKLE, D. W. AND HADLEY, N. F. 1975. Lizard reproductive effort: caloric estimates and comments on its evolution. Ecology, 56, 427-434.

TURELLI, M. 1984. Heritable genetic variation via mutationselection balance. Larch's zeta meets the abdominal bristle. Theor. Popul. Biol., 25, 138-193.

VIA, S. 1984. The quantitative genetics of polyphagy in an insect herbivore. II. Genetic correlations in larval performance within and among host plants. Evolution, 38, 896-913.

VIA, S. AND LANDE, R. 1985. Genotype-environment interaction and the evolution of phenotypic plasticity. Evolution, 39, 505-522.

VIA, S. AND LANDE, R. 1987. Evolution of genetic variability in a spatially heterogeneous environment: effects of genotype $\times$ environment interaction. Genet. Res., 49, 147-156.

VITT, L. J. 1981. Lizard reproduction: habitat specificity and constrains on relative clutch mass. Am. Nat., 117, 506-514.

VITT, L. J. AND CONGDON, J. D. 1978. Body shape, reproductive effort and relative clutch mass in lizards: Resolution of a paradox. Am. Nat., 112, 595-608.

WHITFIELD, D. G. S. 1933. The bionomics and control of Dysdercus (Hemiptera) in the Sudan. Bull. Entomol. Res., 24, 301-313.

williams, G. C. 1966. Adaptation and Natural Selection. Princeton University Press, New Jersey.

wILlows, R. I. 1987. Population dynamics and life history of two contrasting populations of Ligia oceanica (Crustacea: Oniscidea) in the rocky supralittoral. J. Anim. Ecol., 56 , 315-330.

WRIGHT, s. 1931. Evolution in Mendelian populations. Genetics, 16, 97-159. 